\title{
Down-regulation of C12orf59 is associated with a poor prognosis and VHL mutations in renal cell carcinoma
}

\author{
Jun Xie ${ }^{1,2, *}$, Chuangzhi Zhu ${ }^{2, *}$, Jianting $\mathbf{W u}^{1,2}$, Cailing $\mathrm{Li}^{2}$, Liya Luo ${ }^{1}$, Lingling Xia ${ }^{1}$, \\ Xianxin $\mathbf{L i}^{2}$, Yaoting Gui ${ }^{2}$, Zhiming Cai ${ }^{1}$, Zesong $\mathbf{L i}^{1}$ \\ ${ }^{1}$ Shenzhen Key Laboratory of Genitourinary Tumor, Shenzhen Second People's Hospital, First Affiliated Hospital of Shenzhen \\ University, Shenzhen 518035, China \\ ${ }^{2}$ Peking University Shenzhen Hospital, Shenzhen 518036, China \\ *These authors have contributed equally to this work
}

Correspondence to: Zesong Li, e-mail: Izssc@yahoo.com

Keywords: renal cell cancer (RCC), C12orf59, von Hippel-Lindau (VHL), prognosis, survival

Received: November 06, 2014

Accepted: December 26, 2015

Published: January 07, 2016

\section{ABSTRACT}

C12orf59 is newly identified gene in kidney. However, the relation of C12orf59 expression and clinic features is unknown. Here, our study showed that C12orf59 was broadly expressed in normal human tissues with high expression levels in kidney while its expression is beyond detectable in a panel of cancer cell lines. C12orf59 expression in RCC was significantly decreased compared with corresponding adjacent noncancerous tissues $(P<0.01)$. The decreased $C 12$ orf59 expression was correlated with lymph node status $(P<0.05)$, distant metastases $(P<0.05)$, poor survival $(P<0.001)$ (HR 3.00; 95\% CI, 1.29-7.53), VHL non-sense mutations or frame-shift mutations $(P<0.01)$, and UMPP gene non-sense mutations or frame-shift mutations $(P=0.01)$. Thus, we propose that the decreased C12orf59 expression status is a prognostic biomarker of CCRCC and cooperates with the loss of VHL all the while promoting renal carcinogenesis.

\section{INTRODUCTION}

Renal cell carcinoma (RCC), the third most common malignancy of the genitourinary system, accounts for 3\% of all adult malignancies [1]. The incidence of RCC is increasing in most areas of the world for which statistics are available for recent decades [2, 3]. Localized RCC is potentially curable with surgical resection of the diseased tissue, but $30 \%$ of patients develop metastatic disease after surgery. Metastatic RCC remains largely incurable due to its resistance to chemotherapy and radiation [4]. The median survival rate of metastatic RCC patients is 1.5 years, and the five-year survival rate is less than $10 \%$ [5].

Clear cell renal cell carcinoma (ccRCC) is the most common subtype of RCC, accounting for 60 to $80 \%$ of all RCCs [6]. The loss of function of the von Hippel-Lindau $(V H L)$ tumor suppressor gene characterizes ccRCC [7-9]. VHL is a multifunctional protein that acts as an adaptor for different molecular and subcellular complexes. The best-characterized function of VHL is its role as the substrate recognition component of the E3 ubiquitin protein ligase complex that targets the $\alpha$-subunit of the hypoxia-inducible factor (HIF) for proteolytic degradation destruction [10]. In ccRCC, the loss of VHL leads to upregulation of HIF- $\alpha$-mediated transcriptional programs that favor metastatic processes [11].

Recent studies identified several new ccRCC genes, including UTX, JARID1C, SETD2, and BAP1 [12-16]. These studies have heralded a marked expansion in our understanding of the genetic landscape of ccRCC. However, the underlying molecular mechanisms of renal carcinogenesis remain unclear. It is still necessary to identify new signature genes and specific biomarkers in order to provide potential targets for RCC early detection. Furthermore, these targets will allow surveillance of tumor progression, and prediction of patient prognoses [17-21].

The C12orf59 gene (Chromosome 12 open reading frame 59, also termed FLJ31166 [22] or MGC111385 [23]), localized on Chromosome 12p13.2, was first cloned in 2002 [23]. The open reading frame spans $12,847 \mathrm{bp}$, consists of 5 exons, and has 7 transcripts. Human C12orf59 mRNA was associated with the RNA-binding protein HuR [24] and was predicted to encode transmembrane proteins [26]. The classical C12orf59 mRNA (NM 153022.2) is $2800 \mathrm{bp}$ long and encodes a 163 amino acid protein with a calculated relative molecular mass of approximately 
18 kDa (NP_694567.1) [26]. Recently study indicated that the expression of C12orf59 was decreased in RCC [27]. However, the expression and physiological roles of C12orf59 have not been investigated to date.

Here, we report that C12orf59 is frequently decreased at the mRNA and protein levels in a panel of genitourinary cancer cell lines and ccRCC. We found that the decreased C12orf59 expression is associated with renal cell carcinoma clinico-pathological parameters. Therefore, C12orf59 protein level change might be used for clinic marker for RCC early detection, surveillance of tumor progression, and prediction of patient prognoses.

\section{RESULTS}

\section{Tissue distribution of C12orf59 and localization of C12orf59}

C12orf59 is newly identified gene. However, its tissue distribution and subcellular location remains unclear. Our results showed that C12orf59 mRNA was broadly expressed in the majority of the human normal tissues detected, but it was most highly expressed in the kidney (Figure 1A). Immunofluorescence staining showed that C12orf59 was located in the cytoplasm (Figure 1B). Furthermore, cytoplasmic and nuclear extracts were obtained from renal cancer cells stable transfected C12orf59 expression lentivirus. The western blot results showed that the $\mathrm{C} 12$ orf59 protein was primarily detected in the cytoplasm fractions, with no detectable C12orf59 protein in the nuclear fractions (Figure 1C).

\section{Loss of C12orf59 expression in the RCC cell lines and ccRCC}

To test the expression status of C12orf59 in the cancer cell lines, we performed a RT-PCR analysis on a panel of genitourinary cancer cell lines (five renal cancer cell lines: ACHN, Caki-1, 769-P, OS-RC-2 and 786-0; two bladder cancer cell lines: T24 and 5637; three prostate cancer cell lines: PC3, LNCaP and DU145). Our results demonstrated that no detectable C12orf59 mRNA was observed in these cancer cell lines (Figure 2A). This result was confirmed by western blot analysis (Figure 2B).

We previously analyzed the expression profile of ccRCC using deep sequencing technology and revealed that C12orf59 was decreased in a majority of the ccRCC samples compared to the paired non-tumor tissues [27]. To investigate whether C12orf59 expression is altered during carcinogenesis, we performed an in silico analysis of C12orf59 expression in human normal kidney tissues and ccRCC using microarray expression studies published in Oncomine(31). Two independent studies showed that the C12orf59 expression was significantly decreased in the ccRCC samples compared with the normal tissues $(p<0.01)$ (Figure 2C) [28, 29]. We analyzed the expression of C12orf59 in additional 40 paired ccRCC samples and non-tumor tissues. The results showed that the C12orf59 mRNA levels were silenced or strongly decreased in 33 of the $40 \mathrm{ccRCC}$ samples with an overall 4.5-fold decrease in ccRCC compared to the paired nontumor tissues $(P<0.001)$ (Figure 2D). The results were confirmed by western blotting (Figure 2E). IHC staining for $\mathrm{C} 12$ orf59 protein expression in matched tumor and normal tissue confirmed the results and decreased expression in tumor samples across all stages (Figure 2F).

\section{Loss of C12orf59 is correlated with tumor stage, metastasis and poor prognosis}

We examined the possible correlations between the expression levels of $\mathrm{C} 12$ orf59 and the clinical features of ccRCC in 208 primary ccRCC samples. As summarized in Table 1, the patients were assigned to two subgroups according to the expression levels of C12orf59: the low expression group $(n=114)$ and the high expression group $(n=94)$. The C12orf59 low expression group showed more frequent regional lymph node metastases $(P=0.04)$, distant metastases $(P=0.016)$ and late tumor stage $(P=0.014)$ development than the high expression group. The Spearman correlation analysis (Supplementary Table S2) showed that the C12orf59 expression level was significantly inversely correlated with regional lymph node metastases $(P=0.14, P=0.04)$, distant metastases $(P=0.17, P=0.02)$, and late tumor stage $(P=0.17$, $P=0.01)$. No significant correlations between the expression levels of C12orf59 with age, gender and tumor size were observed (Table 1, Supplementary Table S2).

We examined the correlation between the expression status of C12orf59 and the ccRCC prognosis using 122 of the 208 primary ccRCC samples with available follow-up data. As shown in the overall survival curve, the patients in the C12orf59 low expression group (five year survival rate, $52.5 \%$ ) had a significantly poorer prognosis than those in the C12orf59 high expression group (78.9\%, $P<0.001$; Figure 3 ). The median survival time for the patients in the C12orf59 low expression group was 50.1 months as compared to 91.4 months for those in the $\mathrm{C} 12$ orf59 high expression group.

The univariate analysis of the overall survival revealed that the relative level of C12orf59 expression, primary tumor stage, the regional lymph node metastases and distant metastases were prognostic predictors (Table 2). The variables with a $P$ value $<0.05$ were selected for the multivariate analysis. The multivariate analysis showed that the relative level of $\mathrm{C} 12$ orf59 expression, the primary tumor stage, and distant metastases were independent prognostic predictors. The patients with high C12orf59 protein levels in the tumors had a better prognosis than the patients with low C12orf59 protein levels (RR: $-1.40,95 \%$ CI: 0.11-0.57, $P=0.009$; Table 2). 
Genetic deletion or mutation of C12orf59 is not detected in renal cancer cell lines or primary renal cancer tissues

To determine whether genetic alterations contribute to the silencing of C12orf59, we performed sequence screening on the exons and exon-intron junctions of
C12orf59 in 5 renal cancer cell lines and 100 paired ccRCC samples using PCR and direct sequencing. The results showed no somatic mutations/deletions of C12orf59 in the five human renal cancer cells and the 100 paired ccRCC samples, suggesting that the decreased C12orf59 expression might not be caused by genetic alterations.

A
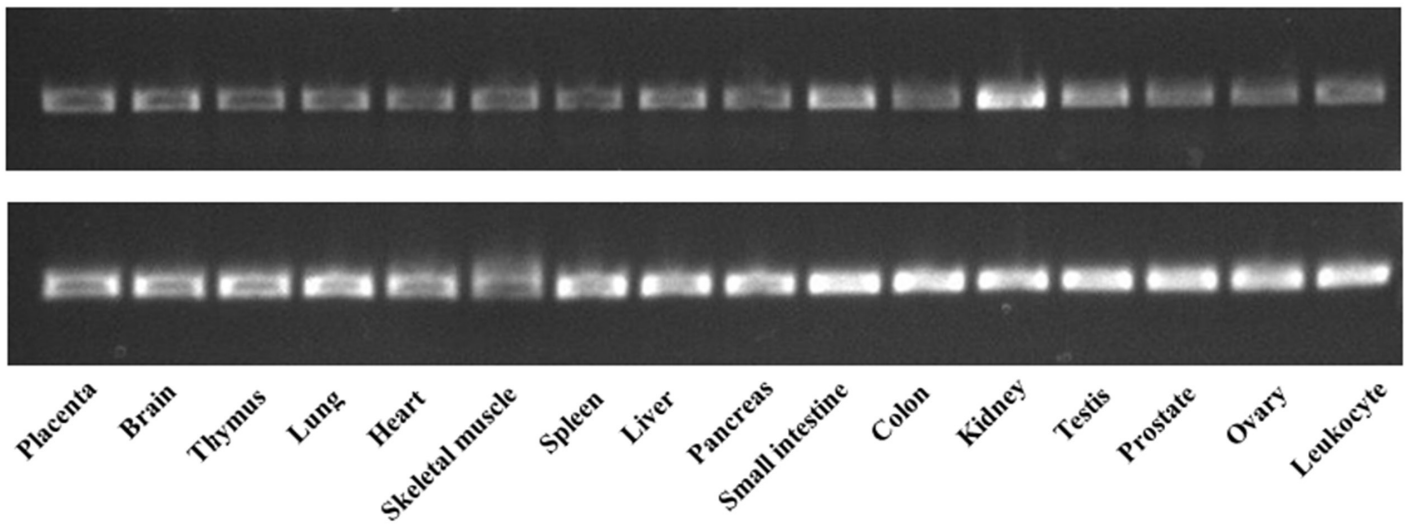

B

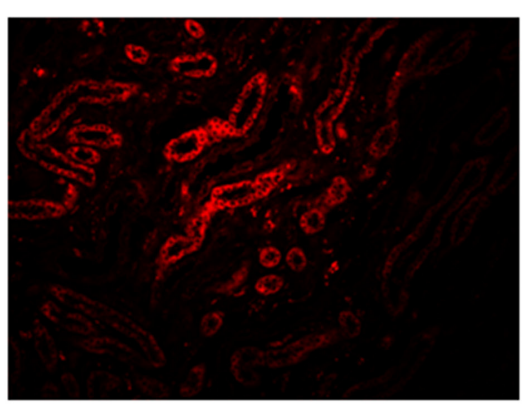

Cy-3

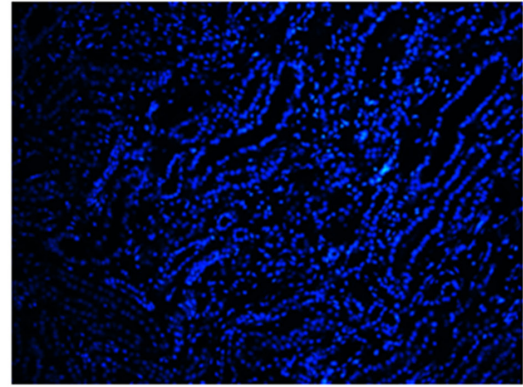

DAPI

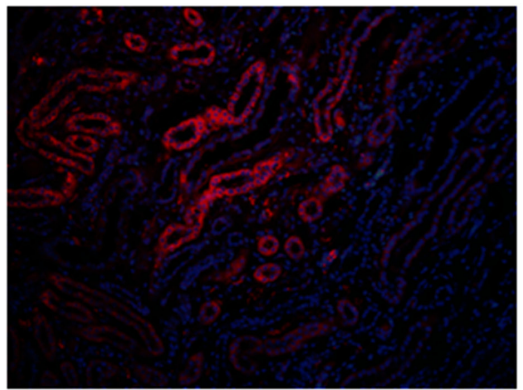

Merge

$\mathrm{C}$

Lenti-Control

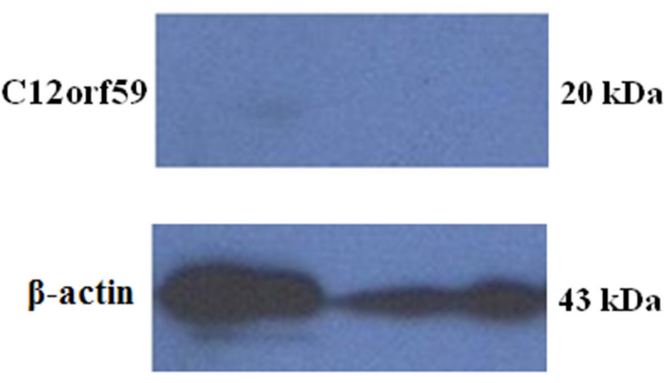

Cytoplasm Nucleus
Lenti-C12orf59

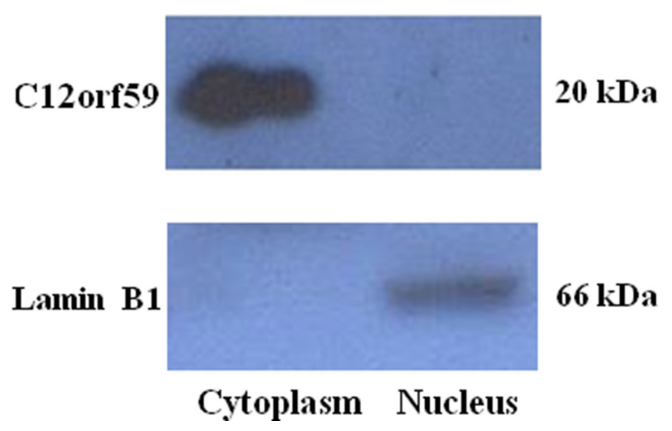

Figure 1: Tissue distribution of C12orf 59 mRNA expression and subcellular localization of the C12orf59 protein in kidney tissues. (A) The C12orf59 mRNA levels were analyzed in a panel of human adult tissues using RT-PCR. $\beta$-actin was used as a loading control. (B) Immunofluorescence staining captured by fluorescence microscope, including Cy-3, DAPI, and merged images. The C12orf59 protein was observed mainly in the cytoplasm. (C) Cytoplasmic and nuclear extracts were obtained from ACHN cells transfected with a lentiviral vector-encoding C12orf59 for western blot analysis, and the C12orf59 protein was detected primarily in the cytoplasm fractions, with no detectable C12orf59 protein in the nuclear fractions. 
Table 1: Correlation between C12orf59 expression and the clinico-pathologic features of patients with clear cell renal cell carcinoma

\begin{tabular}{|c|c|c|c|c|c|}
\hline \multirow{2}{*}{ Clinico-pathologic variables } & \multirow{2}{*}{ No. of cases } & \multicolumn{2}{|c|}{ C12orf59 expression } & \multirow{2}{*}{$\chi^{2}$} & \multirow{2}{*}{$p$} \\
\hline & & low & high & & \\
\hline All cases & 208 & 114 & 94 & & \\
\hline \multicolumn{6}{|l|}{ Gender } \\
\hline Male & 138 & 81 & 57 & 2.503 & 0.114 \\
\hline Female & 70 & 33 & 37 & & \\
\hline \multicolumn{6}{|l|}{ Age } \\
\hline$>50$ & 120 & 71 & 49 & 2.176 & 0.140 \\
\hline$<50$ & 88 & 43 & 45 & & \\
\hline \multicolumn{6}{|l|}{ Size } \\
\hline$>7 \mathrm{~cm}$ & 49 & 24 & 25 & 0.879 & 0.348 \\
\hline$<7 \mathrm{~cm}$ & 159 & 90 & 69 & & \\
\hline \multicolumn{6}{|l|}{ Primary tumor stage } \\
\hline T1-2 & 171 & 87 & 84 & 5.996 & 0.014 \\
\hline T3-4 & 37 & 27 & 10 & & \\
\hline \multicolumn{6}{|l|}{ Lymph node status } \\
\hline N0 & 190 & 100 & 90 & 4.198 & 0.040 \\
\hline $\mathrm{N}+$ & 18 & 14 & 4 & & \\
\hline \multicolumn{6}{|l|}{ Distant metastasis } \\
\hline M0 & 194 & 102 & 92 & 5.789 & 0.016 \\
\hline M1 & 14 & 12 & 2 & & \\
\hline
\end{tabular}

\section{C12orf59 expression is correlated with mutations of the genes encoding the ubiquitin-mediated proteolysis pathway (UMPP)}

As the mutation status of exons was known for 86 ccRCCs [30], we investigated whether C12orf59 expression is correlated with the mutation status of the genes encoding the ubiquitin-mediated proteolysis pathway (Supplementary Table S3). We determined that the fraction of UMPP mutated tumors in the C12orf59 low expression group $(30 / 49,61 \%)$ was similar to that in the C12orf59 high expression group (15/37, 41\%) (Supplementary Table S3), but the fraction of frameshift mutations and non-sense mutations were more frequent in the C12orf59 low expression group than that in the C12orf59 high expression group (39\% vs. $11 \%$, $p=0.006)$. The fraction of the VHL mutated tumors, including whole mutations or frame-shift mutations and non-sense mutations, in the C12orf59 low expression group were more frequent than in the C12orf59 high expression group $(41 \%$ vs. $19 \%, p=0.036 ; 33 \%$ vs. $8 \%, p=0.008$ ) (Figure 4 and Supplementary Table S4). These results indicate that there is a significant correlation between the lack of $\mathrm{C} 12$ orf59 expression and the $V H L$ and UMPP mutations.

\section{C12orf59 expression is not correlated with mutations of the chromatin remodeling genes}

Due to recent sequencing efforts have identified frequent mutations of chromatin remodeling and histonemodifying genes in ccRCC $[12,14,30]$, we analyzed whether C12orf59 expression is associated with the mutation status of these genes (Supplementary Table S5). The results showed that the mutation fraction of the chromatin remodeling genes in the C12orf59 low expression group $(22 / 49,44.9 \%)$ and in the C12orf59 high expression group in ccRCC $(18 / 37,48.6 \%)$ was similar, and the fraction of frame-shift mutations and non-sense mutations were similar (34.7\% vs. $35.1 \%$ ). These data indicate that the lack of C12orf59 expression is not correlated with mutations of the chromatin remodeling genes.

\section{C12orf59 expression is not correlated with HIF1 $\alpha$ and HIF2 $\alpha$ in ccRCC}

Because the HIF $1 \alpha$ and HIF $2 \alpha$ protein levels were known for the 86 ccRCC samples [30], we evaluated the potential correlations between the protein expression patterns of C12orf59, HIF $1 \alpha$ and HIF $2 \alpha$ in ccRCC. As shown in Figure S2, 59.4\% (22/37) of the tumors in the 
Table 2: Univariate and multivariate analyses for overall survival

\begin{tabular}{|c|c|c|c|c|c|c|}
\hline \multirow{2}{*}{ Clinico-pathologic variable } & \multicolumn{3}{|c|}{ Univariate analysis } & \multicolumn{3}{|c|}{ Multivariate analysis } \\
\hline & $\mathbf{R R}$ & $95.0 \% \mathrm{CI}$ & $P$ value & $\mathbf{R R}$ & $95.0 \% \mathrm{CI}$ & $P$ value \\
\hline Gender (male/female) & 0.57 & $0.72-4.31$ & 0.216 & - & - & - \\
\hline Age $(>/<50$ years $)$ & -0.002 & $0.49-2.04$ & 0.995 & - & - & - \\
\hline Size $(>/<7 \mathrm{~cm})$ & -0.52 & $0.33-1.07$ & 0.082 & - & - & - \\
\hline Primary tumor stage (T1-2/T3-4) & 1.37 & $1.92-8.10$ & $<0.001 * * *$ & 0.94 & $1.11-5.92$ & $0.028 *$ \\
\hline Lymph node status (negative/positive) & 1.49 & $2.0-9.92$ & $<0.001 * * *$ & 0.59 & $0.71-4.54$ & 0.231 \\
\hline Distant Metastasis (negative/positive) & 1.59 & $2.06-11.61$ & $<0.001 * * *$ & 1.31 & $1.48-9.28$ & $0.005 * *$ \\
\hline C12orf59 (low/high) & -1.40 & $0.11-0.57$ & $0.001 * *$ & -1.18 & $0.13-0.74$ & $0.009 * *$ \\
\hline
\end{tabular}

Abbreviations: RR; Relative risk, CI; Confidence interval, ${ }^{*} P<0.05, * * P<0.01, * * * P<0.001$

A

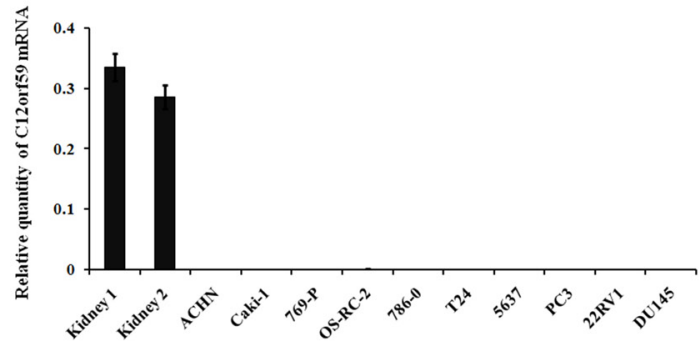

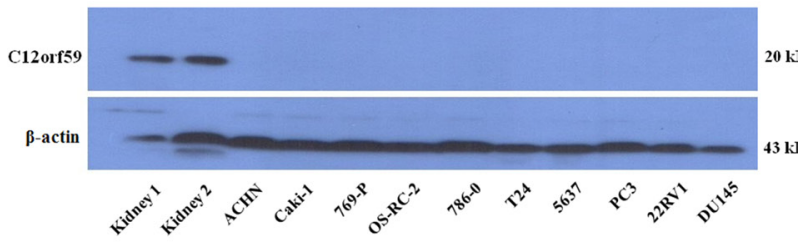

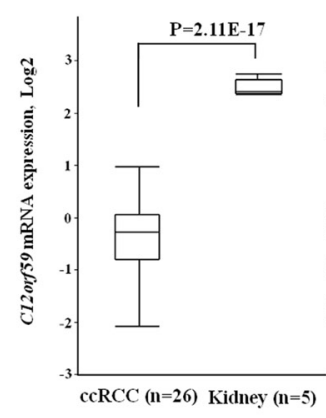

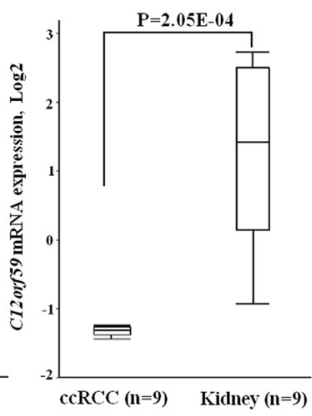

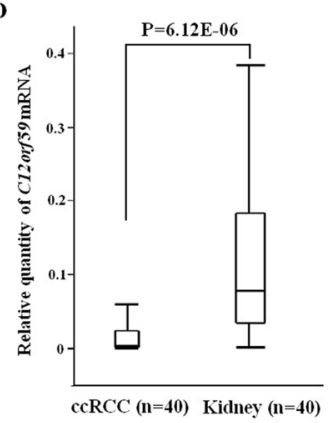

$\mathbf{E}$

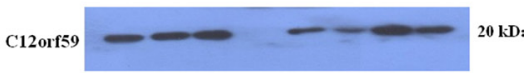

$\beta$-actin

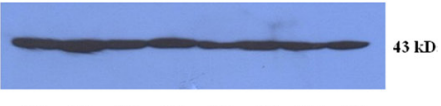

$\begin{array}{lllllllll}\mathrm{N} 1 & \mathrm{C} 1 & \mathrm{~N} 2 & \mathrm{C} 2 & \mathrm{~N} 3 & \mathrm{C} 3 & \mathrm{~N} 4 & \mathrm{C} 4\end{array}$

F

Kidney

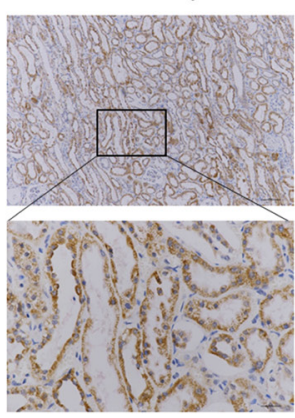

Stage I

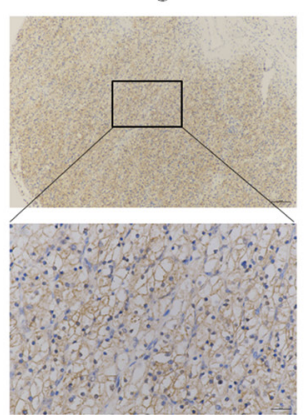

Stage II

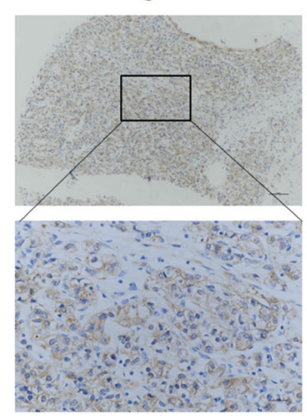

Stage III

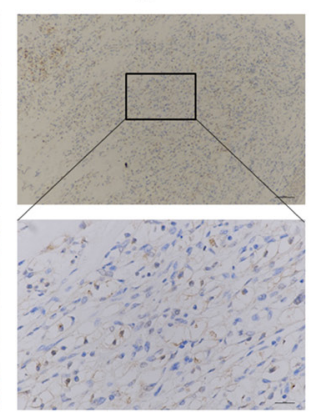

Stage IV

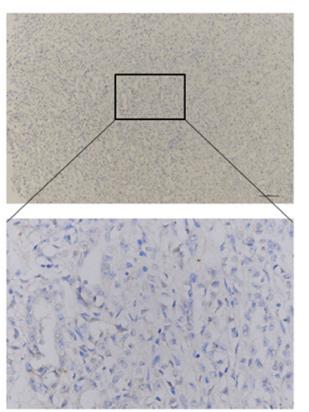

Figure 2: C12orf59 is down-regulated in ccRCC. (A) The quantitative assessment of C12orf59 mRNA levels by real-time PCR in normal kidney tissues, renal cancer cell lines (ACHN, Caki-1, 769-P, OS-RC-2, 786-0), bladder cancer cell lines (T24, 5637), prostate cancer cell lines (PC3, LNCaP, DU145). The data are shown as the mean \pm S.D. for three independent quantifications. (B) The C12orf59 protein in these genitourinary cancer cell lines was detected by western blot. (C) Oncomine was used to analyze the microarray data previously published by Yusenko [28] (left) and Lenburg [29] (right) using standard settings. (D) The expression of C12orf59 in 40 ccRCC and paired noncancerous tissue samples are determined by real-time RT-PCR $(P<0.0001)$. (E) Representative results for the C12orf59 protein in ccRCC and paired noncancerous tissue samples by western blot. (F) Representative immunohistochemical staining for C12orf59 expression in patient normal and ccRCC tissue stage I to IV. 
C12orf59 high expression group were HIF1 $\alpha$ positive, and $26.5 \%(13 / 49)$ of the tumors in the low expression group were HIF1 $\alpha$ negative (Supplementary Figure S2). The correlation between the expression of C12orf59 and HIF $1 \alpha$ was not significant $(P=0.24)$. In addition, $78.4 \%$ (29/37) of the tumors in the C12orf59 high expression group were positive for HIF $2 \alpha$, and $32.6 \%$ (16/49) of the tumors in the C12orf59 low expression group were HIF2 $\alpha$ negative (Supplementary Figure S2). The correlation between the expression of C12orf59 and HIF2 $\alpha$ was not significant $(P=0.33)$. Thus, there was no correlation between the expression of C12orf59 and that of HIF1 $\alpha$ and HIF $2 \alpha$.

\section{DISCUSSION}

We found that the C12orf59 gene was expressed in almost all the tissues, with the highest levels of expression found in the kidney, and that C12orf59 is predominantly a cytosolic protein (Figure $1 \mathrm{~B}$ and $1 \mathrm{C}$ ). The C12orf59 protein is highly conserved among humans, chimpanzees, cows, pigs, mice and rats (Supplementary Figure S1). This ubiquitous expression and conserved sequences of C12orf59 suggested that it might have an important role in the regulation of cell progression.

Our previous study showed that C12orf59 was decreased in a small cohort of ccRCC samples [27]. In the present study, we found that the expression of C12orf59 was lacking in a panel of genitourinary cancer cell lines
(Figure 2A and 2B). By using the silico gene expression data screening Oncomine database [31], we confirmed that the C12orf59 expression in ccRCC is decreased compared with normal tissues (Figure 2C). The results were validated by analyzing the expression of C12orf59 in $40 \mathrm{ccRCC}$ samples and paired noncancerous tissues (Figure 2D and 2E).

To investigate whether C12orf59 expression is correlated with the progression of ccRCC, the C12orf59 expression levels and the clinical pathological characteristics of 208 patients with ccRCC were compared by immunohistochemistry. The results showed that the decreased C12orf59 expression is significantly correlated with the primary tumor stage, lymphatic invasion $(R=0.14, P=0.04)$, and distant metastases $(R=0.17$, $P=0.02$ ) (Table 1), suggesting that decreased C12orf59 expression might be important for the acquirement of malignancy potential in ccRCC. The multivariate analysis revealed that the decreased $C 12$ orf59 expression was a worse independent prognostic factor in ccRCC patients (Figure 3 and Table 2). To our knowledge, this report is the first to demonstrate that C12orf59 has prognostic value as an immunohistochemical biomarker of patient survival in human cancer.

The genetic mechanism of the decreased expression of C12orf59 was investigated by direct sequencing of the gene promoter and exons. No somatic mutations/deletions of 12 orf59 in the five human renal cancer cell lines and 100-paired ccRCC samples were identified. Whether

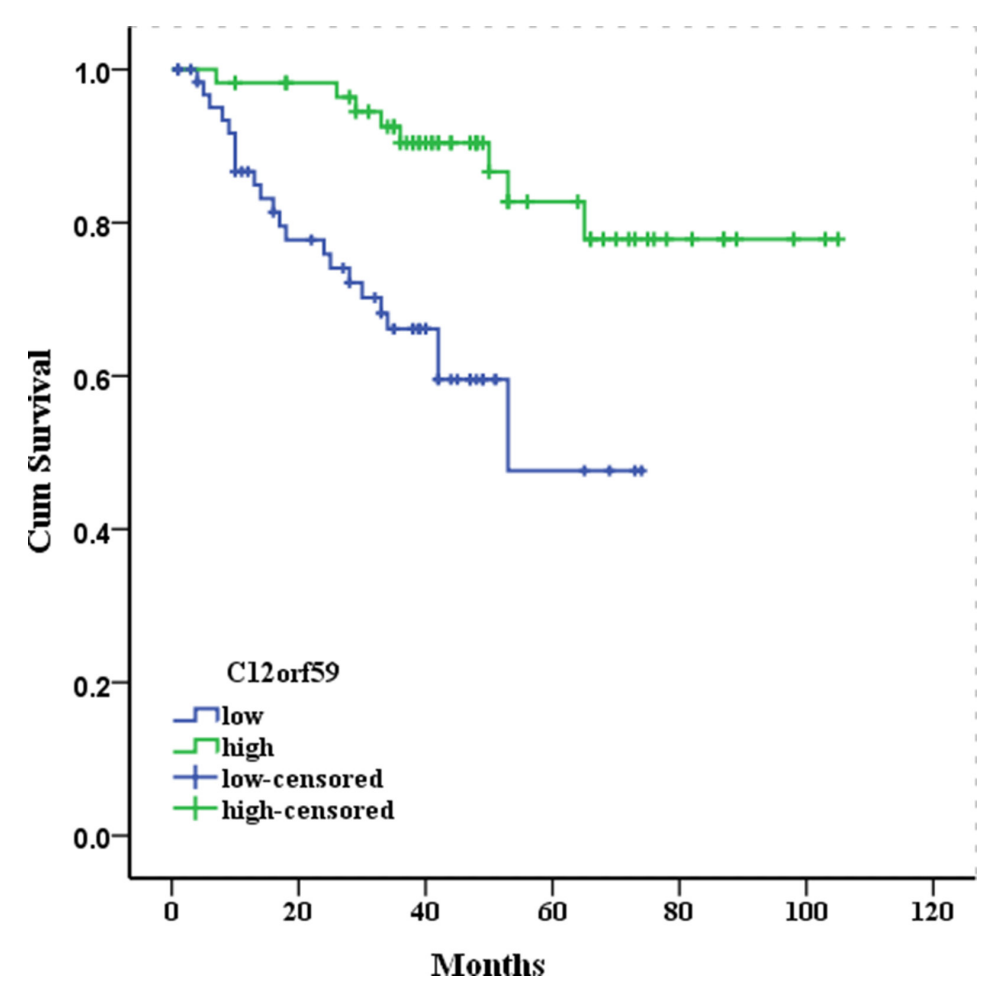

Figure 3: Kaplan-Meier survival curves for 122 patients with clear cell renal cell carcinoma according to C12orf59 expression. The cumulative 5-year survival rate was 78.9\% in the high protein expression group $(n=57)$ and $52.5 \%$ in the low $\mathrm{C} 12$ orf59 expression group $(n=65)(P<0.001)$. 
molecular mechanisms other than mutations, such as promoter hypermethylation, might contribute to C12orf59 silencing remains unknown, but the possibility might reflect genetic and epigenetic events and needs further exploration.

Our analysis revealed that low C12orf59 expression is significantly correlated with the mutation status of genes encoding the ubiquitin-mediated proteolysis pathway, especially with the VHL mutation, but not with mutations of the chromatin remodeling genes. C12orf59 expression is not correlated with HIF $1 \alpha$ or HIF $2 \alpha$, two crucial hypoxia regulatory factors, which were the most intensively investigated VHL target genes. These data suggest that C12orf59 expression is not inhibited by the canonical hypoxia pathway. This raised the possibility that the decrease of $\mathrm{C} 12$ orf59 expression may be provoked by the loss of VHL in a HIF-independent fashion by the same mechanism that VHL influence the p53 expression [32]. We speculated that, in some instances, the decreased C12orf59 expression and the loss of VHL might cooperate to promote the development of ccRCC because VHL inactivation alone is insufficient for tumor initiation $[33,34]$.

In a word, our data provides the first evidence that the loss of C12orf59 expression is a common feature of

A

$\square$ VHL mutation $\quad \square$ VHL wildtype

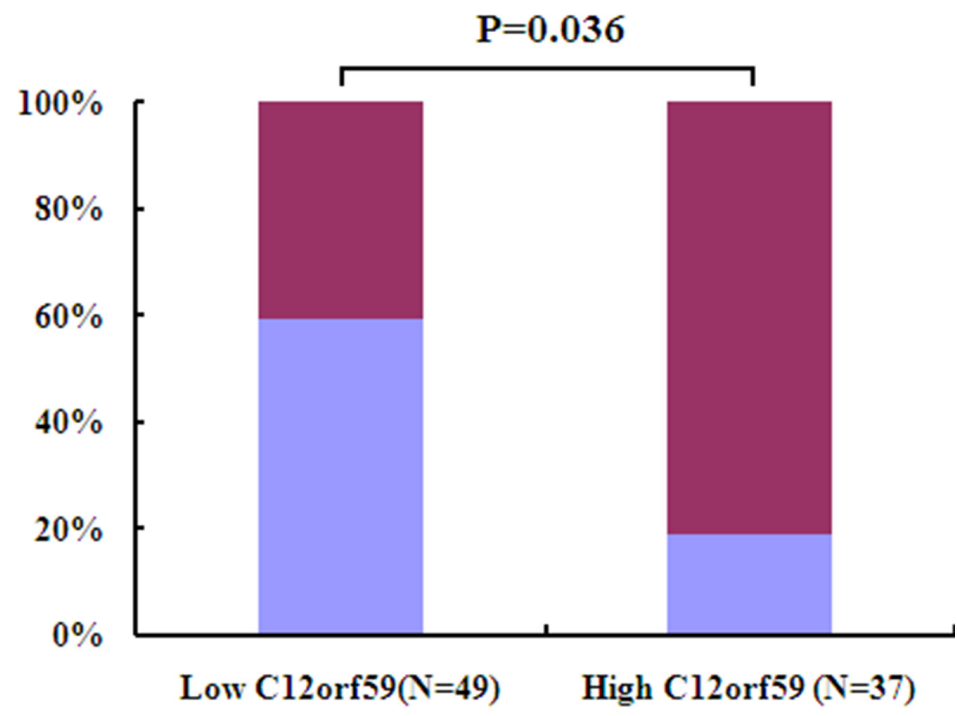

B

$\square$ Frame-shift $\square$ Nonsense $\square$ Missence Indel

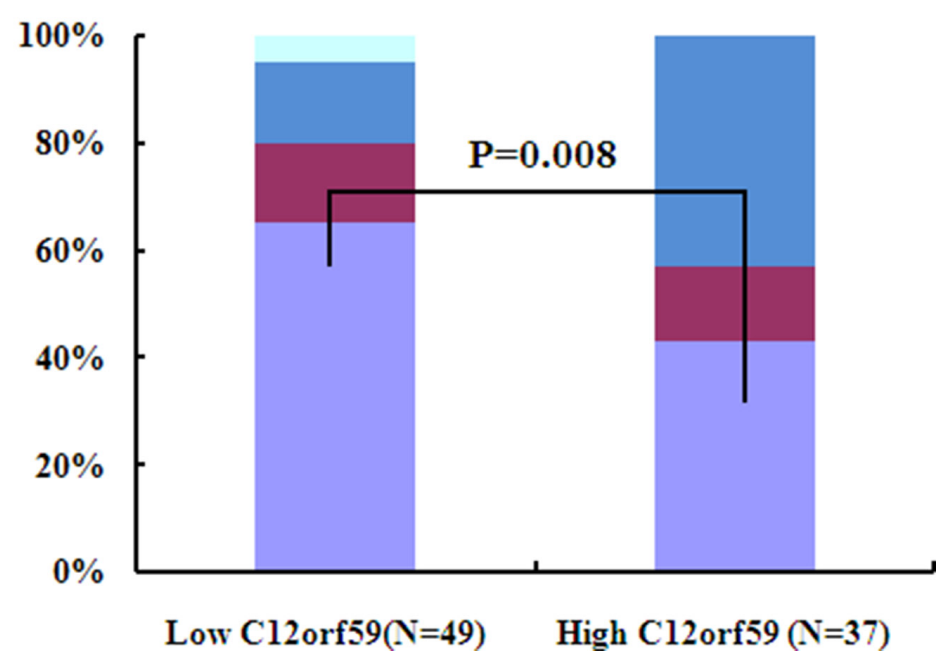

Figure 4: C12orf59 expression is associated with $V H L$ mutation in 88 ccRCC samples. (A) The $V H L$ mutation frequency in the $\mathrm{C} 12$ orf59 low expression group and the C12orf59 high expression group. (B) The distribution of VHL mutation types in the C12orf59 low expression group and the $\mathrm{C} 12$ orf59 high expression group. 
ccRCC that is correlated with increased aggressive tumor behavior and predicts poor survival outcomes of patients. Decreased C12orf59 expression and the loss of VHL may cooperate to promote renal carcinogenesis.

\section{MATERIALS AND METHODS}

\section{Cell culture}

The human renal cell carcinoma cell lines (786-O, OS-RC-2, ACHN, 769-P, and Caki-1), bladder cancer cell lines (T24, 5637), and prostate cancer cell lines (PC3, LNCaP, DU145) were purchased from the American Type Culture Collection (ATCC). All the cell lines were cultured in accordance with the supplier's instructions.

\section{Construction of lentivirus vector and lentivirus infection}

C12orf59 cDNA was cloned into pGV lentivirus vector (Genechem Incorporation, Shanghai, China). The resulting lentivirus vector together with pHelper 1.0 and pHelper 2 vectors were cotransfected into 293FT cells to generate lentiviral stock, and pGV empty vector served as negative control. Forty-eight hours after transfection, supernatant harboring lentiviruses were collected. ACHN cells were infected by lentiviruses in 6-well plates by applying infection cocktail. After 48 hours, infected cells were selected to expand culture for further investigation by using $2 \mu \mathrm{g} / \mathrm{ml}$ of puromycin. Expression of C12orf59 was verified by using real-time PCR and Western blotting.

\section{Tissue samples}

Tissue samples from the tumors with matched normal controls were surgically resected at member institutions of the Urinogenital Cancer Genomics Consortium (UCGC) in China as described previously [30]. Of 100 ccRCC and paired normal kidney tissues, only 86 paires with detailed information were selected for further analysis [30]. An additional 122 paraffinembedded RCC tissue samples with follow-up data were collected from patients between 1999 through 2007. Each patient had provided written informed consent prior to study participation. This study protocol was carried out with ratification by the Ethics Committee of Shenzhen Second People's Hospital. Of these 208 patients, 138 were men, and 70 were women. The median age of the patients was 53 years (range, 4-83 years). The median follow-up time was 39 months (range, 1-105 months). Information regarding the gender, age, stage of disease, and histopathological factors was obtained from the medical records. All the tumors were confirmed as ccRCC by the clinical pathology department of the hospital, and the cases were staged according to the tumor node metastasis staging system.

\section{RT-PCR}

The levels of C12orf59 mRNA in different human adult tissues (Human Multiple Tissue cDNA Panels, I and II) were determined by semi-quantitative PCR with $C 12 \operatorname{orf59}$ primers and $\beta$-actin primers in accordance with the manufacturer's instructions. The levels of C12orf59 mRNA in the cancer cell lines and the tumor and paired normal tissues were determined by a SYBR Green-based real-time PCR assay with $C 12$ orf59 primers, and $\beta$-actin was used as the internal control. The PCR mixture was initially incubated at $94^{\circ} \mathrm{C}$ for 2 minutes, followed by 40 cycles of denaturation at $94^{\circ} \mathrm{C}$ for 15 seconds and annealing and extension at $68^{\circ} \mathrm{C}$ for 30 seconds. The assay was carried out three times in triplicate using the following primer sets: C12orf59-F: 5'-CAGCACTCTCCAGAGCACTATCA-3' and C12orf59-R: 5'- TGGCTACT GTGAAGCGACTCAT-3'; $\beta$-actin-F: 5'-GGCACCACACCTTCTACAATGAG-3'; and $\beta$-actin-R: 5'-GGATAGCACAGCCTGGATAGCA-3'. The relative expression level of $C 12$ orf59 was determined using the $2^{-\Delta \Delta C t}$ method [35].

\section{Database mining}

The Oncomine database [31] was used for retrieving the alterations in the mRNA expression levels in cancers and corresponding disease-free normal and/or normal adjacent tissues.

\section{Immunofluoescence}

For immunofluorescence, the sections were deparaffinized in xylene and rehydrated through graded alcohols, then boiled in $10 \mathrm{mM}$ citrate buffer $(\mathrm{pH} \mathrm{6.0)}$ for $30 \mathrm{~min}$ for the antigen retrieval. The endogenous hydrogen peroxidase was blocked by treating the slides with $3 \%$ hydrogen peroxide and incubating them for $20 \mathrm{~min}$. The section were washed three times in PBS and incubated in TBS containing 5\% BSA for $30 \mathrm{~min}$ at room temperature. The section were incubated with a 1:200 dilution of rabbit polyclonal anti-C12orf59 (ABGENT, CA) in 0.5\% BSA in PBS overnight at $4^{\circ} \mathrm{C}$. The section were washed three times with cold PBS and incubated with a 1:1000 dilution of the secondary antibody donkey anti-rabbit IgG conjugated to $\mathrm{Cy} 3$ (EarthOx, USA) in $0.5 \%$ BSA in PBS for $1 \mathrm{~h}$ at room temperature. After the section were washed three times with PBS and once with water, the nuclei were stained with 4',6-diamidino-2-phenylindol (DAPI) (Sigma, USA). Immunofluorescence was visualized using a fluorescence microscope, and cyanine 3 fluorescence was detected after $100 \%$ excitation at $568 \mathrm{~nm}$.

\section{Western blotting}

The tissues or cells were lysed with a RIPA buffer (Sigma, USA) containing protease inhibitors (Sigma, USA). 
Protein quantification was performed using a BCA protein assay kit (Pierce, USA), and $30 \mu \mathrm{g}$ of total protein were separated in a $12 \%$ gel by SDS-polyacrylamide gel electrophoresis (SDS-PAGE) and transferred to a PVDF membrane (Hybond-P, Amersham Biosciences Piscataway, NJ, USA). After being blocked with 5\% BSA in Tris-buffered saline with $0.1 \%$ Tween 20 (TBST) at room temperature for $2 \mathrm{~h}$, the membrane were probed with primary rabbit anti-C12orf59 antibody (ABGENT, CA) at a dilution of 1:2000 in 5\% skim milk powder in TBST at $4^{\circ} \mathrm{C}$ overnight. After being washed three times with TBST buffer, the blots were incubated with horseradish peroxidase (HRP)-conjugated secondary donkey antirabbit at a dilution of 1:10000 for 1-2 h. After washed three times with TBST buffer, the blotting signals were visualized with ECL systems (Pierce, Rockford, IL, USA). $\beta$-Actin was used as a loading control and was detected with a rabbit mAb (1:1,000 dilution, Novus).

\section{Immunohistochemistry}

Immunostaining of the paraffin-embedded RCC tissue sections was performed by a similar method to that used in our previous work [36]. The sections were deparaffinized and rehydrated, then boiled for the antigen retrieval. The endogenous hydrogen peroxidase was blocked. After being incubated with $10 \%$ BSA, the sections were incubated with anti-C12orf59 antibody (HPA036147, Sigma, USA) used at a 1:300 dilution at $4^{\circ} \mathrm{C}$ overnight. After being washed in PBS, the sections were treated with a MaxVision HRP-Polymer anti-rabbit IHC Kit (Maixin Bio, Fujian, China) and stained with a DAB kit (Maixin Bio, Fujian, China). The expression of C12orf59 was assessed blindly by two independent investigators. The staining of C12orf59 was scored as the product of the staining intensity (on a scale of $0-3$ : negative $=0$, weak $=1$, moderate $=2$, strong $=3$ ) and the percentage of cells stained (on a scale of $1-5: 1=0 \%-20 \% ; 2=21-40 \%$; $3=41-60 \% ; 4=61-80 \% ; 5=81 \%-100 \%$ ), resulting in scores ranging from 0 to 15 . We defined two subgroups as follows: the low expression group (scores: $0-5$ ) and the high expression group (scores: 6-15) [37].

\section{Mutational analyses}

The genomic DNA was extracted from the cells or tissue specimens using the DNeasy Tissue Kit (Qiagen). The PCR primers were designed to cover all the exons, intron/exon junctions, proximal promoter and exon 1 region of the full-length NM_153022.2 mRNA transcript (Supplementary Table S1). The PCR product was subjected to Sanger sequencing to determine the presence or absence of mutations. All the mutations were confirmed at least twice, and the sequence tracings were reviewed in the forward and reverse directions by visual inspection.

\section{Statistical analyses}

All the statistical analyses were carried out using the SPSS 18.0 statistical software package. $\chi^{2}$ tests were used to compare the expression rates of C12orf59 in ccRCC and their adjacent normal kidney tissues and to determine the associations between the expression of C12orf59, HIF $1 \alpha$, HIF $2 \alpha$, and VHL mutation status and the clinicopathological parameters. The bivariate correlations between the variables were calculated by Spearman's correlation coefficients. The multivariate analysis of the relative effect on survival of each parameter included in the univariate analysis was estimated using the Cox proportional hazards regression model. The overall survival rates were determined according to the KaplanMeier method and compared using the log-rank test. $P<0.05$ was statistically significant.

\section{ACKNOWLEDGMENTS AND FUNDING}

Our work was supported by grants from the National Natural Science Foundation of China (Grant No. 81272840, 81472584), the National Key Scientific Program of China (Grant No. 2014CBA02005), Shenzhen Project of Science and Technology (Grant No. 20140416180149160, 201206133000192).

\section{CONFLICTS OF INTEREST}

The authors have no conflicts of interest to declare.

\section{REFERENCES}

1. Siegel R, Naishadham D, Jemal A. Cancer statistics, 2012. CA Cancer J Clin. 2012; 62:10-29.

2. Sun M, Thuret R, Abdollah F, Lughezzani G, Schmitges J, Tian Z, Shariat SF, Montorsi F, Patard JJ, Perrotte P, Karakiewicz PI. Age-adjusted incidence, mortality, and survival rates of stage-specific renal cell carcinoma in North America: a trend analysis. Eur Urol. 2011; 59:135-141.

3. Motzer RJ, Agarwal N, Beard C, Bhayani S, Bolger GB, Carducci MA, Chang SS, Choueiri TK, Hancock SL, Hudes GR, Jonasch E, Josephson D, Kuzel TM, et al. Kidney Cancer. J Natl Compr Canc Ne. 2011; 9:960-977.

4. Cohen HT, McGovern FJ. Renal-cell carcinoma. The N Engl J Med. 2005; 353:2477-2490.

5. Patil S, Ishill N, Deluca J, Motzer RJ. Stage migration and increasing proportion of favorable-prognosis metastatic renal cell carcinoma patients: implications for clinical trial design and interpretation. Cancer. 2010; 116:347-354.

6. Larkin J, Goh XY, Vetter M, Pickering L, Swanton C. Epigenetic regulation in RCC: opportunities for therapeutic intervention? Nat Rev Urol. 2012; 9:147-155.

7. Latif F, Tory K, Gnarra J, Yao M, Duh FM, Orcutt ML, Stackhouse T, Kuzmin I, Modi W, Geil L, et al. Identification 
of the von Hippel-Lindau disease tumor suppressor gene. Science. 1993; 260:1317-1320.

8. Gnarra JR, Tory K, Weng Y, Schmidt L, Wei MH, Li H, Latif F, Liu S, Chen F, Duh FM, et al. Mutations of the VHL tumour suppressor gene in renal carcinoma. Nat Genet. 1994; 7:85-90.

9. Nickerson ML, Jaeger E, Shi Y, Durocher JA, Mahurkar S, Zaridze D, Matveev V, Janout V, Kollarova H, Bencko V, Navratilova M, Szeszenia-Dabrowska N, Mates D, et al. Improved identification of von Hippel-Lindau gene alterations in clear cell renal tumors. Clin Cancer Res. 2008; 14:4726-4734.

10. Metelo AM, Noonan H, Iliopoulos O. HIF2a inhibitors for the treatment of VHL disease. Oncotarget. 2015; 6:23036-23037. doi: 10.18632/oncotarget.4564.

11. Frew IJ, Krek W. pVHL: a multipurpose adaptor protein. Sci Signal. 2008; 1:pe30.

12. Dalgliesh GL, Furge K, Greenman C, Chen L, Bignell G, Butler A, Davies H, Edkins S, Hardy C, Latimer C, Teague J, Andrews J, Barthorpe S, et al. Systematic sequencing of renal carcinoma reveals inactivation of histone modifying genes. Nature. 2010; 463:360-363.

13. van Haaften G, Dalgliesh GL, Davies H, Chen L, Bignell G, Greenman C, Edkins S, Hardy C, O’Meara S, Teague J, Butler A, Hinton J, Latimer C, et al. Somatic mutations of the histone H3K27 demethylase gene UTX in human cancer. Nat Genet. 2009; 41:521-523.

14. Varela I, Tarpey P, Raine K, Huang D, Ong CK, Stephens P, Davies H, Jones D, Lin ML, Teague J, Bignell G, Butler A, Cho J, et al. Exome sequencing identifies frequent mutation of the SWI/SNF complex gene PBRM1 in renal carcinoma. Nature. 2011; 469:539-542.

15. Pena-Llopis S, Vega-Rubin-de-Celis S, Liao A, Leng N, Pavia-Jimenez A, Wang S, Yamasaki T, Zhrebker L, Sivanand S, Spence P, Kinch L, Hambuch T, Jain S, et al. BAP1 loss defines a new class of renal cell carcinoma. Nat Genet. 2012; 44:751-759.

16. Kapur P, Pena-Llopis S, Christie A, Zhrebker L, PaviaJimenez A, Rathmell WK, Xie XJ, Brugarolas J. Effects on survival of BAP1 and PBRM1 mutations in sporadic clear-cell renal-cell carcinoma: a retrospective analysis with independent validation. Lancet Oncol. 2013; 14:159-167.

17. von Roemeling CA, Marlow LA, Wei JJ, Cooper SJ, Caulfield TR, Wu K, Tan WW, Tun HW, Copland JA. Stearoyl-CoA desaturase 1 is a novel molecular therapeutic target for clear cell renal cell carcinoma. Clin Cancer Res. 2013; 19:2368-2380.

18. Lu D, Dong D, Zhou Y, Lu M, Pang XW, Li Y, Tian XJ, Zhang Y, Zhang J. The tumor-suppressive function of UNC5D and its repressed expression in renal cell carcinoma. Clin Cancer Res. 2013; 19:2883-2892.

19. Xiao H, Zeng J, Li H, Chen K, Yu G, Hu J, Tang K, Zhou H, Huang Q, Li A, Li Y, Ye Z, Wang J, et al. MiR-1 downregulation correlates with poor survival in clear cell renal cell carcinoma where it interferes with cell cycle regulation and metastasis. Oncotarget. 2015; 6:13201-13215. doi: 10.18632/oncotarget.3915.

20. Chen K, Yu G, Gumireddy K, Li A, Yao W, Gao L, Chen S, Hao J, Wang J, Huang Q, Xu H, Ye Z. ZBRK1, a novel tumor suppressor, activates VHL gene transcription through formation of a complex with VHL and p300 in renal cancer. Oncotarget. 2015; 6:6959-6976. doi: 10.18632/oncotarget.3134.

21. Ghosh AP, Marshall CB, Coric T, Shim EH, Kirkman $\mathrm{R}$, Ballestas ME, Ikura M, Bjornsti MA, Sudarshan S. Point mutations of the mTOR-RHEB pathway in renal cell carcinoma. Oncotarget. 2015; 6:17895-17910. doi: 10.18632/oncotarget.4963.

22. Ota T, Suzuki Y, Nishikawa T, Otsuki T, Sugiyama T, Irie R, Wakamatsu A, Hayashi K, Sato H, Nagai K, Kimura K, Makita H, Sekine M, et al. Complete sequencing and characterization of 21,243 full-length human cDNAs. Nat Genet. 2004; 36:40-45.

23. Strausberg RL, Feingold EA, Grouse LH, Derge JG, Klausner RD, Collins FS, Wagner L, Shenmen CM, Schuler GD, Altschul SF, Zeeberg B, Buetow KH, Schaefer CF, et al. Generation and initial analysis of more than 15,000 full-length human and mouse cDNA sequences. Proc Natl Acad Sci USA. 2002; 99:16899-16903.

24. Abdelmohsen K, Srikantan S, Yang X, Lal A, Kim HH, Kuwano Y, Galban S, Becker KG, Kamara D, de Cabo R, Gorospe M. Ubiquitin-mediated proteolysis of $\mathrm{HuR}$ by heat shock. EMBO J. 2009; 28:1271-1282.

25. Clark HF, Gurney AL, Abaya E, Baker K, Baldwin D, Brush J, Chen J, Chow B, Chui C, Crowley C, Currell B, Deuel B, Dowd P, et al. The secreted protein discovery initiative (SPDI), a large-scale effort to identify novel human secreted and transmembrane proteins: a bioinformatics assessment. Genome Res. 2003; 13:2265-2270.

26. Gerhard DS, Wagner L, Feingold EA, Shenmen CM, Grouse LH, Schuler G, Klein SL, Old S, Rasooly R, Good P, Guyer M, Peck AM, Derge JG, et al. The status, quality, and expansion of the NIH full-length cDNA project: the Mammalian Gene Collection (MGC). Genome Res. 2004; 14:2121-2127.

27. Zhou L, Chen J, Li Z, Li X, Hu X, Huang Y, Zhao X, Liang C, Wang Y, Sun L, Shi M, Xu X, Shen F, et al. Integrated profiling of microRNAs and mRNAs: microRNAs located on Xq27.3 associate with clear cell renal cell carcinoma. PloS one. 2010; 5:e15224.

28. Yusenko MV, Kuiper RP, Boethe T, Ljungberg B, van Kessel AG, Kovacs G. High-resolution DNA copy number and gene expression analyses distinguish chromophobe renal cell carcinomas and renal oncocytomas. BMC cancer. 2009; 9:152.

29. Lenburg ME, Liou LS, Gerry NP, Frampton GM, Cohen HT, Christman MF. Previously unidentified changes in renal cell carcinoma gene expression identified by parametric analysis of microarray data. BMC cancer. 2003; 3:31. 
30. Guo G, Gui Y, Gao S, Tang A, Hu X, Huang Y, Jia W, Li Z, He M, Sun L, Song P, Sun X, Zhao X, et al. Frequent mutations of genes encoding ubiquitin-mediated proteolysis pathway components in clear cell renal cell carcinoma. Nat Genet. 2011; 44:17-19.

31. Rhodes DR, Kalyana-Sundaram S, Mahavisno V, Varambally R, Yu J, Briggs BB, Barrette TR, Anstet MJ, Kincead-Beal C, Kulkarni P, Varambally S, Ghosh D, Chinnaiyan AM. Oncomine 3.0: genes, pathways, and networks in a collection of 18,000 cancer gene expression profiles. Neoplasia. 2007; 9:166-180.

32. Roe JS, Kim H, Lee SM, Kim ST, Cho EJ, Youn HD. p53 stabilization and transactivation by a von Hippel-Lindau protein. Mol Cell. 2006; 22:395-405.

33. Mandriota SJ, Turner KJ, Davies DR, Murray PG, Morgan NV, Sowter HM, Wykoff CC, Maher ER, Harris AL, Ratcliffe PJ, Maxwell PH. HIF activation identifies early lesions in VHL kidneys: evidence for sitespecific tumor suppressor function in the nephron. Cancer Cell. 2002; 1:459-468.
34. Montani M, Heinimann K, von Teichman A, Rudolph T, Perren A, Moch H. VHL-gene deletion in single renal tubular epithelial cells and renal tubular cysts: further evidence for a cyst-dependent progression pathway of clear cell renal carcinoma in von Hippel-Lindau disease. Am J Surg Pathol. 2010; 34:806-815.

35. Livak KJ, Schmittgen TD. Analysis of relative gene expression data using real-time quantitative PCR and the 2(-Delta Delta C(T)) Method. Methods. 2001; 25:402-408.

36. Li Z, Chim JC, Yang M, Ye J, Wong BC, Qiao L. Role of PCDH10 and its hypermethylation in human gastric cancer. Mol Cell Res. 2011; 1823:298-305.

37. Spizzo G, Fong D, Wurm M, Ensinger C, Obrist P, Hofer C, Mazzoleni G, Gastl G, Went P. EpCAM expression in primary tumour tissues and metastases: an immunohistochemical analysis. J Clin Pathol. 2011; 64:415-420. 